\title{
Simplified approach to assess the dynamic response of a container ship subjected to bow slamming load
}

\author{
K. Wołoszyk \& M. Bogdaniuk \\ Polish Register of Shipping, Gdańsk, Poland \\ Faculty of Ocean Engineering and Ship Technology, Gdansk University of Technology, Gdańsk, Poland
}

\begin{abstract}
Simplified approach to assess the dynamic response of a container ship subjected to the bow slamming load, resulting in a transient vibratory response, typically called a 'whipping', is presented. The accurate numerical modelling is very complex and involves coupling of the hydrodynamic and structural solution at every time step, leading to huge computational and workload cost. Thus, the one-way coupling methodology is adopted, and hydrodynamic loads are derived using linear strip theory in the first step and applied to the FE beam model. Structural response is obtained in the time domain using an explicit dynamic solver. Extreme bending moment is derived and compared with the normative values of the wave-induced bending moment. Comparing to more accurate methods, the presented approach seems to overestimate the bending moment and leads to a conservative design. Thus, it may be used in the early stages of the design, where fast and reliable methods are essential.
\end{abstract}

\section{INTRODUCTION}

During heavy sea conditions, the ship's bow oscillates vertically, resulting in impulsive highpressure values, called slamming. This results in transient vibrations of the ship. The occurrence of whipping could be visible in Figure 1, where stress measurements at the weather deck during a full-scale sea trial of the frigate are presented (Tuitman 2010). The response seems to be non-impulsive in general; however, after around 1355 seconds, the ship starts to whip. The stresses are notably increased concerning quasi-static response. The slamming loading increases not only global response, but local pressure loads are increased as well. The transient vibratory response could be critical not only for ships but for inland structures too, e.g. bridges (Wang et al. 1992) or railway tracks (Costa et al. 2010).

The whipping response is well known for many ship types (Aalberts and Nieuwenhuijs 2006). Due to the rapid growth of container ships size, whipping becomes a more important effect influencing ship structural response. Container ships have relatively low stiffness in comparison to their length. In recent years, the problem was analysed in the experimental and numerical domain. In the experiments, both model tests (Storhaug et al. 2010) and full-scale measurements (Gaidai et al. 2016, Mao et al. 2015) were carried out. In model testing, the tests are usually quite expensive, and only a limited number of cases could be investigated. It is very hard to simulate the flexibility of the real ship. The results of such experiments are also subjected to high uncertainties. In numerical calculations, many authors explored different modelling techniques (Barhoumi and Storhaug 2014, Malenica and Derbanne 2014).

The numerical modelling of whipping is very complex and involves coupling of the hydrodynamic and structural solution at every time step. The whipping simulation tool must consist of hydrodynamic (seakeeping and slamming), structural and coupling part. In each of these parts, different modelling method could be adopted. Even separate modelling of nonlinear 


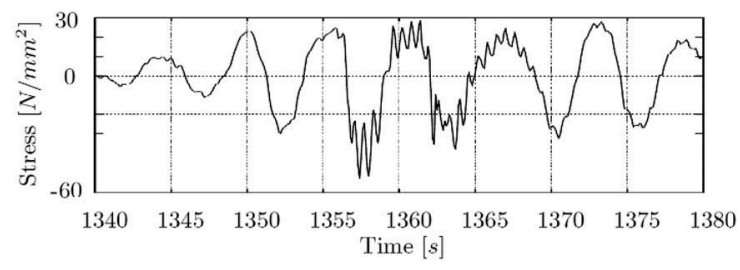

Figure 1. Measured stress during full-scale trials of the frigate (Tuitman 2010).

hydrodynamic part is very challenging. The procedure used for hydroelastic analysis utilises the potential flow theory for the hydrodynamic part, and 3D FE or beam model for the structural part. Nowadays, seakeeping models based on complex CFD calculations were developed. However, there are very sensitive to different numerical parameters and require huge CPU requirements.

Although the two-way coupled approach gives the most accurate results regarding whipping contribution, the one-way coupled approach could be adopted for the first estimation. This type of approach could be adopted in the initial design stage to avoid very complicated calculations. In the presented analysis, the hydrodynamic loading and structural response are assumed to be independent.

\section{SHIP MOTIONS ANALYSIS}

In the final strength assessment case, the three-dimensional seakeeping calculations are to be performed to obtain the ship motions. However, for the first estimation, the simplified ship motion closed-form expressions presented by Jensen et al. 2004 could be utilised, where the ship hull is considered non-deformable.

The frequency response functions for a box-shaped vessel can be derived analytically by the linear strip theory (Gerritsma and Beukelman 1964). The equations of motions (heave and pitch) for a given wave amplitude $a$ are equal to (Jensen 2001):

$$
\frac{2 k T}{\omega^{2}} \ddot{w}+\frac{A^{2}}{k B \alpha^{3} \omega} \dot{w}+w=a F \cos \left(\omega_{e} t\right) ; \frac{2 k T}{\omega^{2}} \ddot{\theta}+\frac{A^{2}}{k B \alpha^{3} \omega} \dot{\theta}+\theta=a G \sin \left(\omega_{e} t\right)
$$

where $k$ is the wave number, $\omega$ is the wave frequency, $B$ and $T$ are the breadth and draft of the box. The encounter frequency $\omega_{e}$ is equal to $\omega_{e}=\omega-k V \cos \beta=\alpha \omega$, where $V$ is the ships forward speed, $\beta$ is the heading angle (180 degrees for head sea), $\alpha=1-\left(\frac{k V}{\omega}\right) \cos \beta$.

The sectional hydrodynamic damping is modelled as a ratio between incoming and diffracted wave amplitude: $A=2 \sin \left(0.5 k B \alpha^{2}\right) \exp \left(-k T \alpha^{2}\right)$, the forcing functions $F$ and $G$ are then equal to:

$$
F=\kappa f \frac{2}{k_{e} L} \sin \left(\frac{k_{e} L}{2}\right) ; G=\kappa f \frac{24}{\left(k_{e} L\right)^{2} L}\left[\sin \left(\frac{k_{e} L}{2}\right)-\frac{k_{e} L}{2} \cos \left(\frac{k_{e} L}{2}\right)\right]
$$

where $k_{e}=|k \cos \beta|$ is the effective wave number and $f=\sqrt{(1-k T)^{2}+\left(\frac{A^{2}}{k B \alpha^{3}}\right)^{2}}$. The Smith correction factor $\kappa$ is taken approximately as $\kappa=\exp \left(-k_{e} T\right)$.

Solutions of Equations 1 result in frequency response functions: $\phi_{w}=\eta F ; \phi_{\theta}=\eta G$, where $\eta=\left(\left(1-2 k T \alpha^{2}\right)^{2}+\left(\frac{A^{2}}{k B \alpha^{2}}\right)^{2}\right)^{-\frac{1}{2}}$.

The resulting frequency response functions for the vertical motion $u=w \quad x \theta$ and the velocity $v=\omega_{e}(w-x \theta)$ in a longitudinal position, $x$ from the centre of gravity are equal to:

$$
\phi_{u}=\sqrt{\phi_{w}^{2}+x^{2} \phi_{\theta}^{2}} ; \phi_{v}=\omega_{e} \phi_{u}
$$


However, to evaluate the slamming load, one needs the relative vertical motion $r(x, t)$ concerning the wave elevation $h(x, t): r(x, t)=w(t) \quad x \theta(t) \quad h(x, t)$. The relative motion in a position $x$ is equal to:

$$
\phi_{r}=\sqrt{\left(\phi_{w}-\cos \zeta(x)\right)^{2}+\left(x \phi_{\theta}+\sin \zeta(x)\right)^{2}}
$$

where $\zeta(x)=\varepsilon_{e}+\varepsilon_{r}+k_{e} x$, and $\varepsilon_{e}$ and $\varepsilon_{r}$ need to satisfy the following terms:

$$
\cos \varepsilon_{e}=1-\frac{k T}{f} ; \sin \varepsilon_{e}=\frac{A^{2}}{k B \alpha^{3} f} ; \cos \varepsilon_{r}=\left(1-2 k T \alpha^{2}\right) \eta ; \sin \varepsilon_{r}=-\frac{A^{2}}{k B \alpha^{2}} \eta
$$

The presented equations are derived for the box-shaped floating object. To evaluate the ship motions, the breadth $B$ is replaced by the $B C_{b}$.

\section{BOW FLARE SLAMMING LOAD}

To estimate the slamming load acting on a bow of a containership, the simplified equations shown by Zhao and Faltinsen 1993 could be used. The bow hull geometry is treated as a wedge (see Figure 2a).

The impact force per unit length due to slamming in a particular moment can be approximated as:

$$
q(t)=3 C_{p} \rho v^{3} t_{s}
$$

where $C_{p}=\frac{\pi^{2}}{4 \tan ^{2} \alpha}$, is the dynamic pressure coefficient, $\rho$ is the water density, $\alpha$ is the deadrise angle of wedge section and $t_{s}$ is the time accounting for the water rise-up at maximum immersion, equal to:

$$
t_{s}=\frac{2 B_{l} \tan \alpha}{6 v}
$$

where $B_{l}$ is the local breadth, which could be calculated equal to $B_{l}=\frac{\Delta H}{\tan \alpha}$, and $\Delta H=0.75$ (Depth Draft) in $\mathrm{m}$.

The section which represents the slamming section could be taken at the location $x=0.95 \mathrm{~L}$. The deadrise angle $\alpha$ is a mean from the four points as presented in Figure $2 \mathrm{~b}$.

\section{NUMERICAL EXAMPLE}

\subsection{Analysed ship}

As a reference model for the whipping analysis, the 14500 TEU container ship has been chosen. The ship dimensions are: length between perpendiculars of $347 \mathrm{~m}$, breadth of $48.2 \mathrm{~m}$, depth of $29.85 \mathrm{~m}$ and the general arrangement of the ship is presented in Figure 3 .

a)

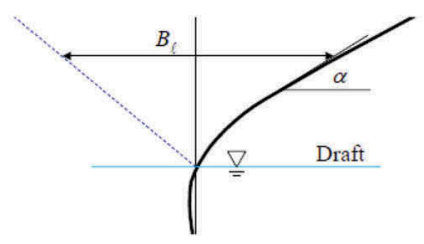

b)

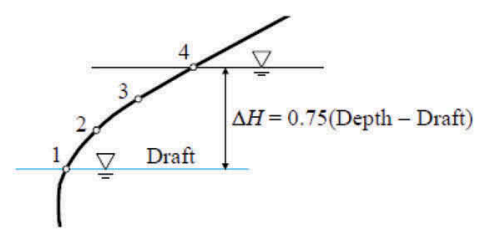

Figure 2. Deadrise angle and local breadth of wedge section a) and calculation procedure b) (American Bureau of Shipping 2014). 


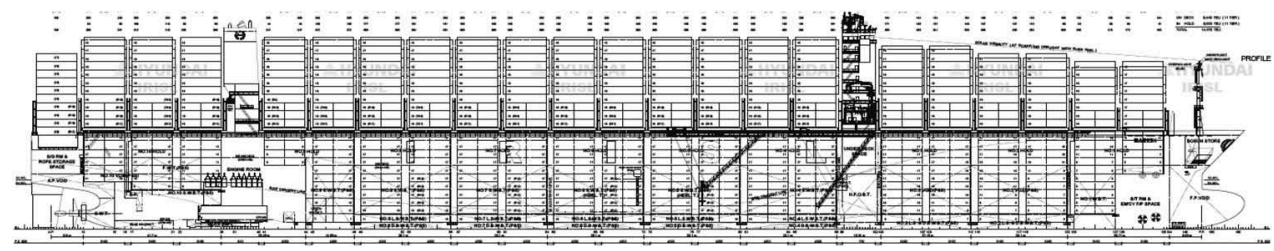

Figure 3. The general arrangement of the container ship.

\subsection{Slamming force}

The 25-year significant wave height is considered as presented in IACS Recommendation 34 (International Association of Classification Societies 2001), considering regular wave. The slamming force is calculated for all wave periods, and the wave height, which maximises the slamming force, is chosen. Figure 4 presents the dependency between the wave period and the slamming force.

The maximum slamming force is for a wave height of $15.3 \mathrm{~m}$ and a period of 11.5 seconds. For that wave height, one can consider the $0.25 \mathrm{~V}$ as a ship speed. The service speed for the considered ship is equal to 22 knots, so 5.5 knots is the velocity for a particular wave height.

The wave length can be estimated equal to:

$$
\lambda=\frac{2 \pi g}{\omega^{2}}=\frac{2 \pi 9.81}{0.5236^{2}}=224.8 \mathrm{~m}
$$

The encounter frequency for a considered case is equal to $0.5236 \mathrm{rad} / \mathrm{sec}$. The coefficient of sectional hydrodynamic damping $A$ is calculated equal to 0.3541 . The forcing functions $F$ and $G$ are equal to 0.38592 and 0.005624 , respectively. The resulting ship motions are as follows: bow motion $-10.355 \mathrm{~m}$, bow velocity $-5.973 \mathrm{~m} / \mathrm{s}$, relative bow motion $-17.638 \mathrm{~m}$, relative bow velocity $-10.175 \mathrm{~m} / \mathrm{s}$. The latter value is used to calculate the slamming load.

The slamming section's local breadth is equal to $11.3 \mathrm{~m}$, and the deadrise angle is equal to 45.6 degrees. The maximum slamming force is equal to:

$$
F_{S L}=0.01 L \frac{\pi^{2}}{\tan ^{2} \alpha} \rho v^{2} \Delta H=0.01 \cdot 347 \frac{\pi^{2}}{\tan ^{2} 45.6} 1.025 \cdot 10.175^{2} \cdot 11.51=40.23[M N]
$$

\section{$4.3 \quad$ FE model}

Based on the information about weight distribution and the longitudinal variation of the cross-sectional moment of inertia, the beam model employing CBEAM elements and

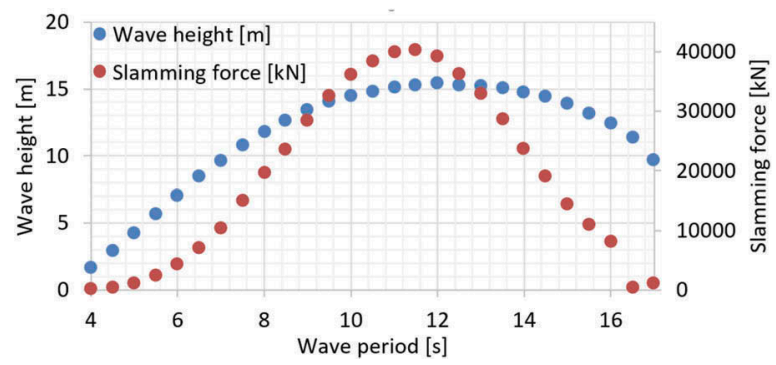

Figure 4. Slamming force in the function of wave period. 


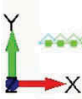

Figure 5. FE model of the container ship with the applied load.

commercial software FEMAP has been prepared. The assessment of dynamic transient response is done with the assumption that the bending moments generated by the slamming load could be superimposed with the still water and wave-induced bending moments. Nevertheless, one needs to consider missing boundary conditions. It is well known that the ship hull can be considered as a beam with spring supports. Each node is supported by the spring element having two characteristics: stiffness and damping. The sectional stiffness can be calculated from the buoyancy force:

$$
k_{i}=\rho g B_{i} l_{i}
$$

where $B_{i}$ is the ship breadth on the waterline in the longitudinal position of the considered node and $l_{i}$ is the mean length of the adjacent elements.

Furtherly, the sectional hydrodynamic damping can be calculated as follows:

$$
b_{i}=2 A \sqrt{k_{i} m_{i}}
$$

where $A$ is the hydrodynamic sectional damping, $k_{i}$ is the hydrodynamic sectional stiffness calculated from Eq. 10 and $m_{i}$ is the total mass of the considered section.

Lastly, it needs to be pointed that during ship vibrations, not only the hull mass is oscillating, but hull induces the acceleration of some amount of fluid mass. This effect is needed to be included as additional inertia to the system, and it is well-known as a so-called 'added mass'. The added mass of the section is assumed as a mass of displaced water. The added mass is incorporated in the FE model by adding non-structural mass to the beam elements.

The slamming time-history is modelled as a linear function starting from a zero value at the moment that bow is hitting the wave up to the maximum value within the time $t_{s}$ as calculated by Eq. 7, and then drops to 0 value again. The total duration of the simulation is taken 5 seconds, as a multiplication of a couple of vibration periods of the lowest natural mode, which was obtained by solving an eigenvalue problem. Furtherly, the time step has been derived as a fraction of one of the highest natural modes. The beam FE model with the applied slamming load as a nodal force is presented in Figure 5.

\section{RESULTS AND DISCUSSION}

The bending moment time-histories for each section are derived. In Figure 6, the bending moment charts for sections in $1 / 4$, half and $3 / 4$ of the ship length are presented. Notable, in the midship section, the bending moment is dominated by 2-node vibrations. In the case of sections in $0.25 \mathrm{~L}$ and $0.75 \mathrm{~L}$, the bending moment results from the superposition of 2-node and 3-node vibrations. Apart from these major contributors, the influence of other vibration modes is visible too. The bending moment is in the range between -2000 MNm up to $2000 \mathrm{MNm}$.

Nevertheless, the maximum bending moment is obtained for the section located in $0.4 \mathrm{~L}$. The value of the maximum bending moment is equal to $2509 \mathrm{MNm}$ in hogging condition. In the case of the sagging condition, the maximum bending moment is equal to $2304 \mathrm{MNm}$.

To see the influence of whipping-induced bending moment, the maximum value from Section 6 is compared with the wave-induced bending moments calculated in accordance with IACS UR S11A (International Association of Classification Societies 2015). 


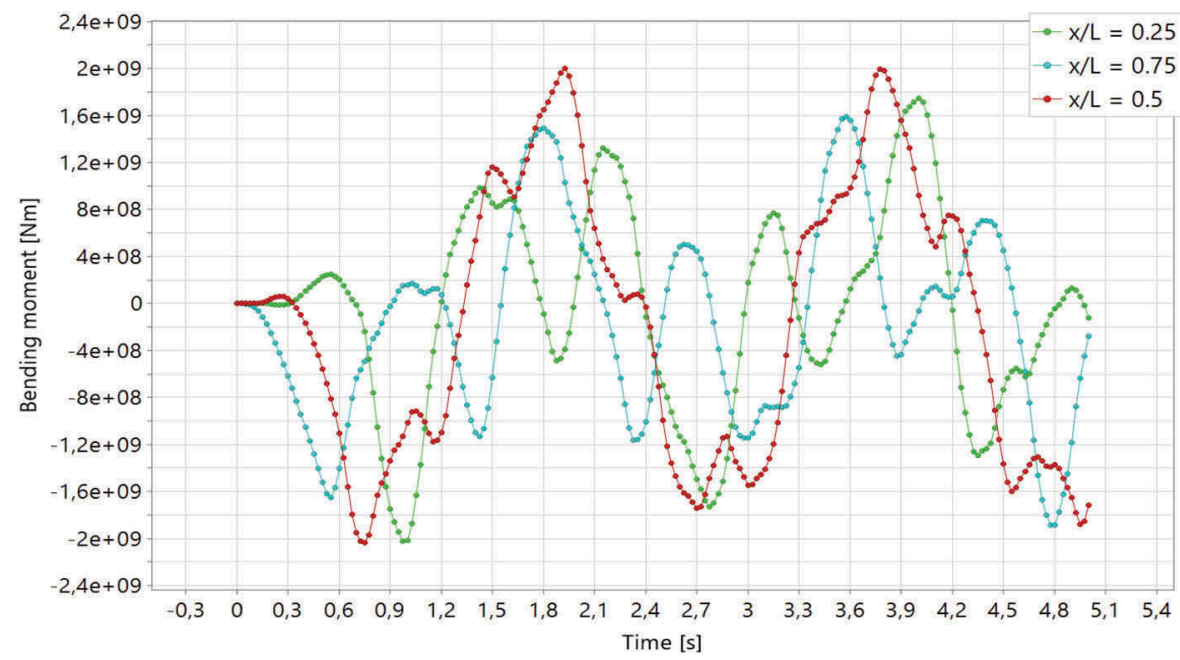

Figure 6. The bending moment $[\mathrm{Nm}]$ time-history for cross-sections $\mathrm{x}=0.25 \mathrm{~L}, \mathrm{x}=0.5 \mathrm{~L}$ and $\mathrm{x}=0.75 \mathrm{~L}$.

Table 1. Influence of whipping moment in the total dynamic bending moment.

\begin{tabular}{|c|c|c|c|c|}
\hline & $\begin{array}{l}\text { Wave-induced } \\
\text { moment } M_{w}\end{array}$ & $\begin{array}{l}\text { Whipping bending } \\
\text { moment } M_{\text {whip }}\end{array}$ & $M_{w h i p} / M_{w}$ & $\begin{array}{l}\text { Total bending } \\
\text { moment }\end{array}$ \\
\hline & {$[\mathrm{MNm}]$ (UR S11A) } & {$[\mathrm{MNm}]$} & {$[\%]$} & {$[\mathrm{MNm}]$} \\
\hline Hogging & 8462 & 2509 & 29.7 & 10971 \\
\hline Sagging & 9233 & 2304 & 25.0 & 11537 \\
\hline
\end{tabular}

The comparison of whipping contribution for both sagging and hogging condition is presented in Table 1.

It could be concluded that whipping phenomena significantly impact the total dynamic bending moment and need to be considered from the beginning of the analysis of the strength of container ships. Nevertheless, when compared with the fully coupled analysis (Tuitman 2010, Malenica and Derbanne 2014), the whipping influence could be possibly overestimated.

\section{CONCLUSIONS}

The presented work investigated the whipping influence on the container ship's longitudinal strength, using a simplified approach. Compared to the more advanced techniques, the proposed method was swift and practical, especially when considering initial design stages. The calculated influence of whipping bending moment into the wave-induced bending moment reached the level of $30 \%$, which seems to be overestimated value when compared to the fully coupled analysis, which could lead to the conservative design. The maximum bending moment has been achieved in the section lying on the 0.4 lengths of the ship and not in the middle. The 2-node vibrations were the main component influencing the bending moment in the midship cross-section, whereas, in the case of sections located in the $1 / 4$ and $3 / 4$ of the ship's length, both 2 -node, as well as 3 -node vibration modes, contributed to the bending moment value. 


\section{REFERENCES}

Aalberts P.J., and Nieuwenhuijs M. 2006. Full scale wave and whipping induced hull girder loads. In 4th. Int. Conf. on Hydroelasticity. Wuxi, China.

American Bureau of Shipping. 2014. Guidance notes on whipping assessment for container carriers.

Barhoumi, M., and Storhaug, G. 2014. Assessment of whipping and springing on a large container vessel. International Journal of Naval Architecture and Ocean Engineering. 6(2): 442-458.

Bian, X., Cheng, C., Jiang, J., Chen, R., Chen., Y. 2016. Numerical analysis of soil vibrations due to trains moving at critical speed. Acta Geotechnica, 11: 281-294.

Gaidai, O., Storhaug, G., and Naess, A. 2016. Extreme large cargo ship panel stresses by bivariate ACER method. Ocean Engineering, 123: 432-439.

Gerritsma, J., and Beukelman, W. 1964. The distribution of the hydrodynamic forces on a heaving andpitched shipmodel in still water. International Shipbuilding Progress. 11(123): 506-522.

International Association of Classification Societies. 2001. Recommendations. 34. Standard Wave Data.

International Association of Classification Societies. 2015. Unified Requirements. S11A. Longitudinal Strength Standard for Container Ships.

Jensen, J. J. 2001. Load and global response of ships. Elsevier.

Jensen, J. J., Mansour, A. E., \& Olsen, A. S. 2004. Estimation of ship motions using closed-form expressions. Ocean Engineering. 31(1): 61-85.

Malenica, S., and Derbanne, Q. 2014. Hydro-structural issues in the design of ultra large container ships. International Journal of Naval Architecture and Ocean Engineering. 6(4): 983-999.

Mao, W., Li, Z., Ogeman, V., \& Ringsberg, J. W. 2015. A regression and beam theory based approach for fatigue assessment of containership structures including bending and torsion contributions. Marine Structures. 41: 244-266.

Storhaug, G., Malenica, S., Choi, B. K., Zhu, S., \& Hermundstad, O. A. 2010. Consequence of whipping and springing on fatigue and extreme loading for a 13000TEU container vessel based on model tests. In 11th International Symposium on practical design of ships and other floating structures. Rio de Janeiro, Brazil (pp. 19-24).

Tuitman, J. T. 2010. Hydro-elastic response of ship structures to slamming induced whipping (Doctoral dissertation, Dissertation of Delft University of Technology).

Wang, T. L., Huang, D., Shahawy, M. 1992. Dynamic response of multigirder bridges. Journal of Structural Engineering. 118(8): 2222-2238.

Zhao, R., and Faltinsen, O. 1993. Water entry of two-dimensional bodies. Journal of Fluid Mechanics. 246: 593-612. 